\title{
INTERMITTENT SMALL BASELINE SUBSET (ISBAS) INSAR ANALYSIS TO MONITOR LANDSLIDES IN COSTA DELLA GAVETA, SOUTHERN ITALY
}

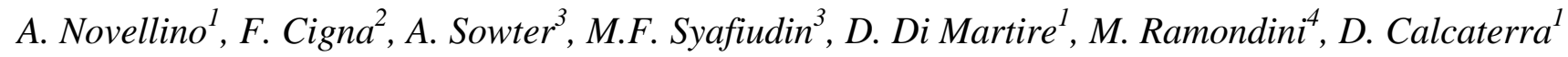 \\ ${ }^{1}$ Department of Earth Sciences, Environment and Resources, Federico II University of Naples, Naples, Italy. \\ ${ }^{2}$ British Geological Survey, Keyworth, United Kingdom. \\ ${ }^{3}$ University of Nottingham, Nottingham, United Kingdom. \\ ${ }^{4}$ Department of Civil, Architectural and Environmental Engineering, Federico II University of Naples, Naples, Italy.
}

\begin{abstract}
This work presents a Differential SAR Interferometry (DInSAR) analysis of slow-moving landslides in Costa della Gaveta (southern Italy) exploiting the improved spatial density of radar targets provided by the novel Intermittent SBAS (ISBAS) algorithm. Several landslides occurred in this area over the past decade, producing a ground displacement of several centimeters and causing unsafe road and rail traffic conditions. In the $2.4 \mathrm{~km}^{2}$ study area, ISBAS analysis of TerraSAR-X data acquired in 2010-2011 has shown the presence of sixteen phenomena with a southeastern main direction of motion. The DInSAR results agree with both the magnitude and the deformation mechanisms that were mapped during field observations and reported in the geotechnical literature.
\end{abstract}

Index Terms - DInSAR, ISBAS, landslide, Costa della Gaveta

\section{INTRODUCTION}

Space-borne Synthetic Aperture Radar (SAR) is a powerful and efficient remote sensing technique to monitor surface changes due to natural or human induced processes. In particular, DInSAR Interferometry (DInSAR) allows the measurement of ground displacements by properly analyzing the phase difference between multiple SAR images acquired over the same area at different times and orbital positions [1]. DInSAR allows the generation of surface deformation maps relevant to very large areas, and achieving precisions at millimetric level. The technique started to be routinely used for landslide mapping and monitoring in the last decade, thus becoming a well-established method to study the geomorphology and topography of slope deformation [2].

Costa della Gaveta slope in southern Italy poses a challenge to traditional slope investigation tools (e.g., photogrammetry, benchmarks, theodolites, total stations, GPS, inclinometers), due to the difficulty in applying these techniques to analyze an area extending $2.4 \mathrm{~km}^{2}$, mainly represented by agricultural terrains. This impediment resulted in five significantly different landslide inventory maps for the corresponding study area, where slope failures damaged several road connections, private homes, and commercial buildings [3-5]. At the same time conventional DInSAR techniques might be severely compromised to monitor surface motions in areas where few scatterers or coherent targets exist. While the newly developed Intermittent SBAS (ISBAS) technique can fill the gap by providing a more complete picture of ground movement in rural and vegetated regions and thus enabling easier interpretations [6]. The ISBAS algorithm was recently developed at the Nottingham Geospatial Institute of the University of Nottingham and successfully applied in [7].

In this work, we apply ISBAS to TerraSAR-X ascending data acquired during the timespan 10/02/201026/04/2011. The DInSAR displacements have been corroborated with geological field surveys, aerial photo interpretation and ground truth data that consists of monitoring records from twenty-seven inclinometers, twelve piezometers and fifteen GPS stations.

\section{GEOLOGICAL SETTING}

Costa della Gaveta is located along the left bank of the Basento river (Figure 1) along a slope whose elevation ranges between 760 and $820 \mathrm{~m}$ a.s.l. with an angle of $8^{\circ}$; the instabilities affect the shales of the Varicoloured Clays Unit (Upper Cretaceous - Lower Miocene) and, partially, marly limestones and calcarenite of the Corleto Perticara Formation (Upper Eocene - Lower Miocene) [8]. The high liquid limit of the clay-rich layers, the residual strength of the superficial softened layer together with a deeper soil with a far higher peak strength and the highly tectonized fabric of the terrains en bloc represent likely factors for failure, of flow or slide typology, to occur. The pervasive extensional NW-SE jointing affecting the Varicoloured Clays Unit also determines a preferential path for the hydrographic network and the mass movements. 


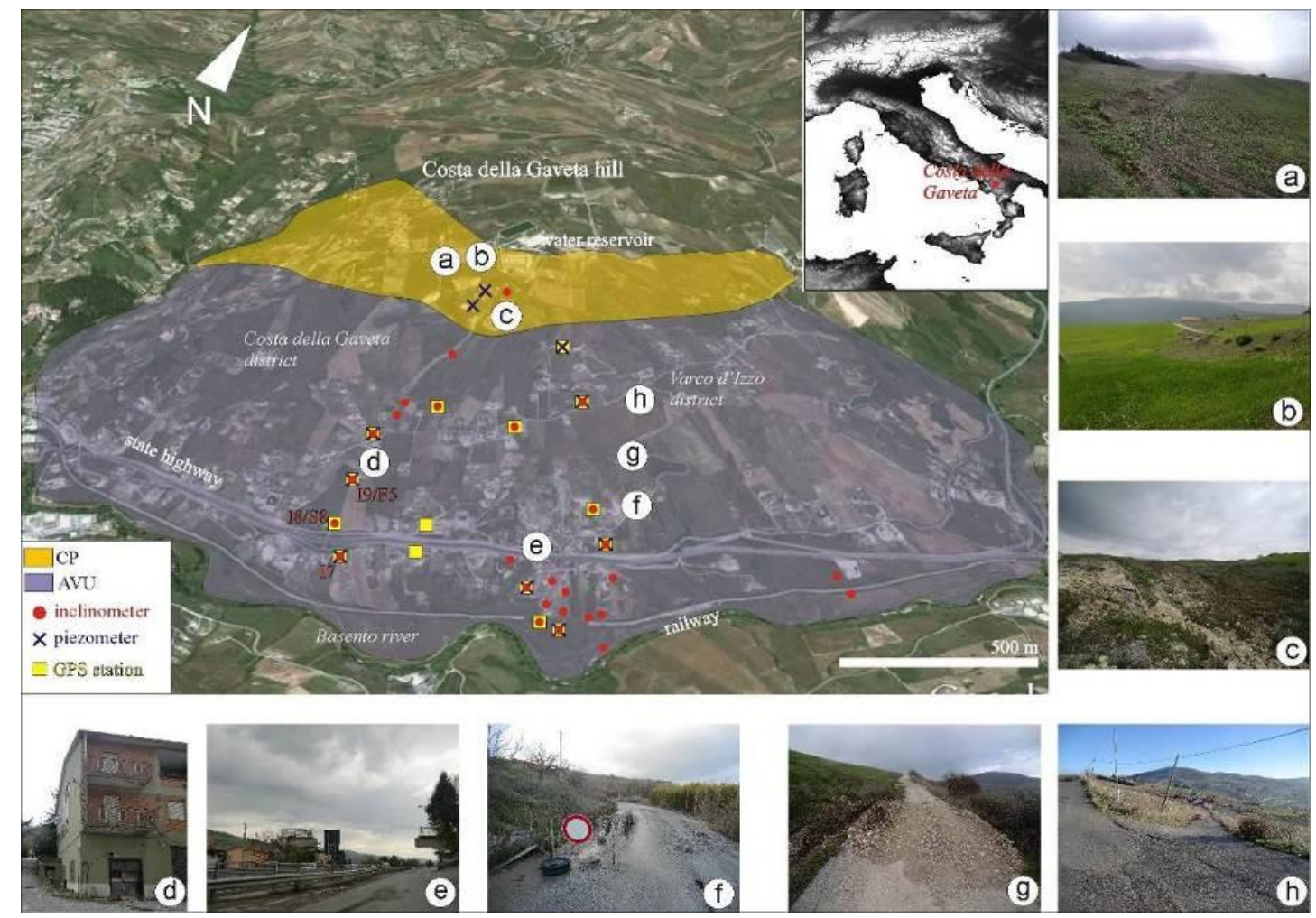

Figure 1 - 3D sketch of Costa della Gaveta hill from the southeastern side and field evidences of the corresponding damage, with location of inclinometers, piezometers and GPS stations. CP: Corleto Perticara Formation; AVU: Varicoloured Clays Unit.

Mass movements, in turn, show viscous behaviour with multiple kinematic units due to the heterogeneity of the materials involved and the occurrence of slip surfaces at different depths (ranging from $40 \mathrm{~m}$ to $15 \mathrm{~m}$ ). These conditions make the in situ sensors and surveying, only available at the locations shown in Figure 1, insufficient or even misleading in describing landslide phenomena affecting this slope. These are not going to stabilise naturally, due to the Basento river erosion which allows for the steady soil discharge in the accumulation zones that stretches for about $1 \mathrm{~km}$ width in correspondence to the highway.

\section{ISBAS ANALYSIS}

Twenty-nine TerraSAR-X StripMap images $50 \mathrm{~km}$ by $50 \mathrm{~km}$ wide, acquired during the 10/02/2010 - 26/04/2011 timespan in ascending geometry with an incidence angle of $37^{\circ}$ and $3 \mathrm{~m}$ nominal resolution were used in the ISBAS processing. A multi-looking factor of $5 \times 5$ (azimuth $\mathrm{x}$ range) was employed to increase the phase signal quality and reduce radar speckle, and this increased the corresponding size of the image pixels on the ground to $\sim 15 \mathrm{~m}$.

Based on the multi-looked scenes, a set of 267 small baseline interferograms was generated by employing a perpendicular baseline threshold of $300 \mathrm{~m}$ and a temporal baseline threshold of 365 days. The condensed temporal and spatial distribution of the acquisitions permitted to minimize phase decorrelation components in the outcomes and enhance phase quality of the processed pixels (hence coherence $-\gamma$ ).

The resulting $\gamma$ of the processed subset was generally moderate despite the absence of temporal gaps in the stack, with the majority of the scene showing average values between 0.2 and 0.4 , and only built-up areas, corresponding to the infrastructures along the Basento valley, showed higher coherences, namely between 0.4 and 1 . By adopting a $\gamma$ threshold of 0.7, implementation of the Coherent Pixels Technique [9] led to an average target density of $\sim 500$ points $/ \mathrm{km}^{2}$ for the same area of interest [10]. With the ISBAS algorithm only those pixels showing coherence higher than 0.5 were employed for the unwrapping step, provided that the number of coherent interferograms for those pixels exceeded 50. The latter threshold was used for the selection of intermittently coherent targets across the stack of differential interferograms, allowing a trade-off between uncertainty in the ISBAS solutions and the targets spatial coverage that resulted in $\sim 7,300$ points $/ \mathrm{km}^{2}$ (Figure 2). 


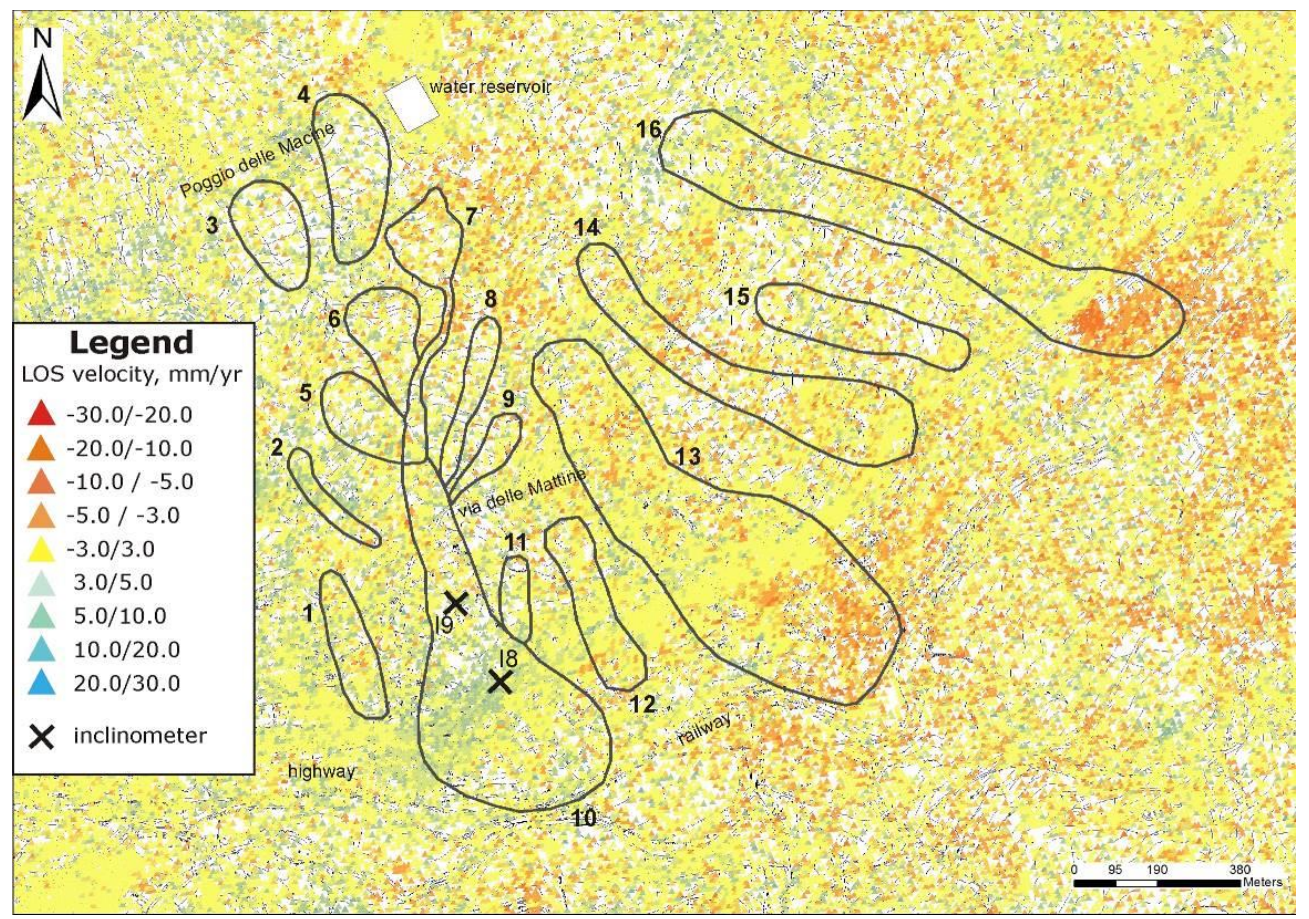

Figure 2 - ISBAS LOS velocities retrieved in the Costa della Gaveta area with location of the three inclinometers employed for the comparison. Black lines indicate the mapped landslide boundaries.

\section{RESULTS AND INTERPRETATION}

Figure 2 shows the map of the TerraSAR-X Line Of Sight displacement velocities in 2010-2011, with values ranging between $-21.5 \mathrm{~mm} / \mathrm{year}$ nearby the 19 inclinometer and $+19.2 \mathrm{~mm} /$ year along the neck area of landslide no.7. Accounting for the $2 \mathrm{~mm} /$ year standard error, points showing velocities within $\pm 3 \mathrm{~mm} /$ year were considered stable. Landslides no.10, no.13 and no.16 showed a distinct number of radar targets within their boundaries moving faster than $\pm 3 \mathrm{~mm} /$ year. Other landslides did not show ISBAS unstable points due to their stability in 2010-2011. In Figure 3 TerraSAR-X time series are compared to two inclinometric displacement profiles (I8 and I9) providing information on the upper remoulded soil where shear creep rates are higher [11].

The peculiar shape of landslides (i), with a scarp at the top of the state highway and a bulge of material at the base of it, the upwards velocities at the toe of landslide no.10 (ii) and the abrupt change in state of activity of landslides no.13 and 16 (iii), which turns out to be active just downstream the road, demonstrate the role of sheet pile walls, road embankments and deep foundations in slowing down the slope movements.

Despite the high seismicity of the area, the earthquakes registered within a radius of $20 \mathrm{~km}$ from Costa della Gaveta, show a low peak ground deformations associated with their magnitude, suggesting that earthquakes did not trigger new landslides or reactivated dormant ones during the interval monitored with TerraSAR-X.
According to the Potenza rain gauge station, rainfall shows strong correlation with displacements. This is particularly evident at the beginning of November 2010 when more than $250 \mathrm{~mm}$ of rainfall accumulated in less than 15 days, compared to the $40 \mathrm{~mm}$ that generally characterizes the same period, determining movements of more than 10 $\mathrm{mm}$ in over 97,700 ISBAS points shown in Figure 3. The latter suggests that rainfall led to a deviation from the trend seen in the ISBAS time series.

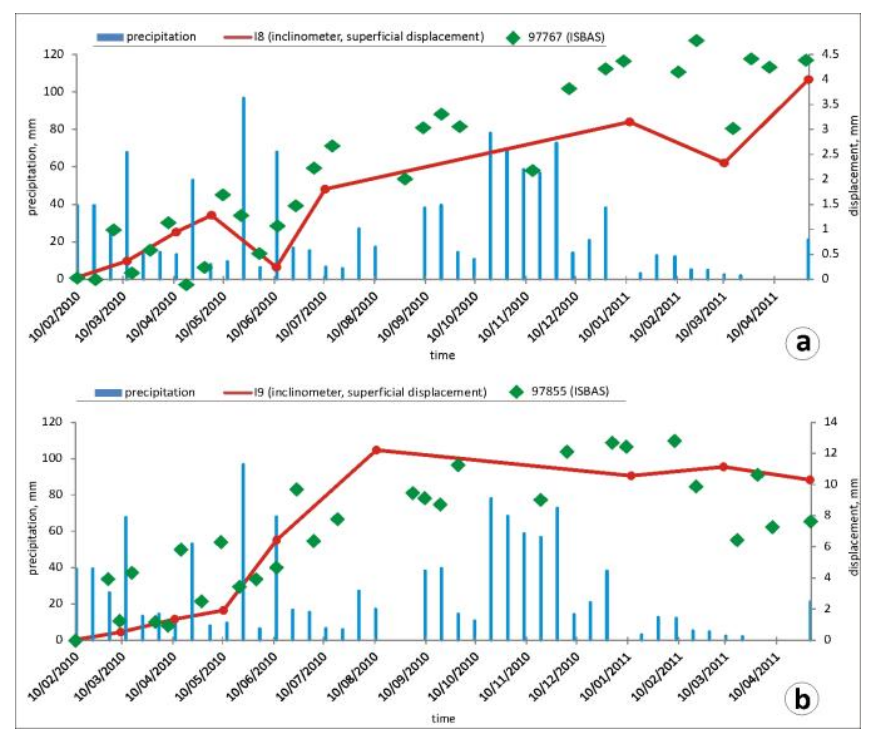

Figure 3 - Comparison between ISBAS time-series and inclinometer readings at positions I8 (a) and I9 (b). Also illustrated are precipitation measurements. 


\section{CONCLUSION}

Information gathered within the geomorphological investigation (lithology, slope, aspect, land use, flow accumulation, road distance, ISBAS velocities, structural features and landslide boundary) were finally integrated for the evaluation of the landslide susceptibility map, following the Weight of Evidence (WoE) bivariate statistical method [12]. In this method, landslide conditioning factors are singularly overlapped with the landslide inventory map and the frequency statistics are calculated from their combinations in terms of the the importance of the presence/absence of each factor for the landslide occurrence.

The WoE map in Figure 4 reveals that the slope aspect represents the most influential factors and, therefore, higher susceptibility characterizes the southeastern sector of the Costa della Gaveta hill, especially where cohesionless and poorly sorted slope debris crops out.

Only small and scattered portions of the SE-facing slope shows low to moderate landslide susceptibility, due to lower slope angle, that is drastically reduced on the southwest facing slopes. The overall susceptibility is still high despite the physical countermeasures enacted to downgrade it during the last ten years (e.g., concrete walls).

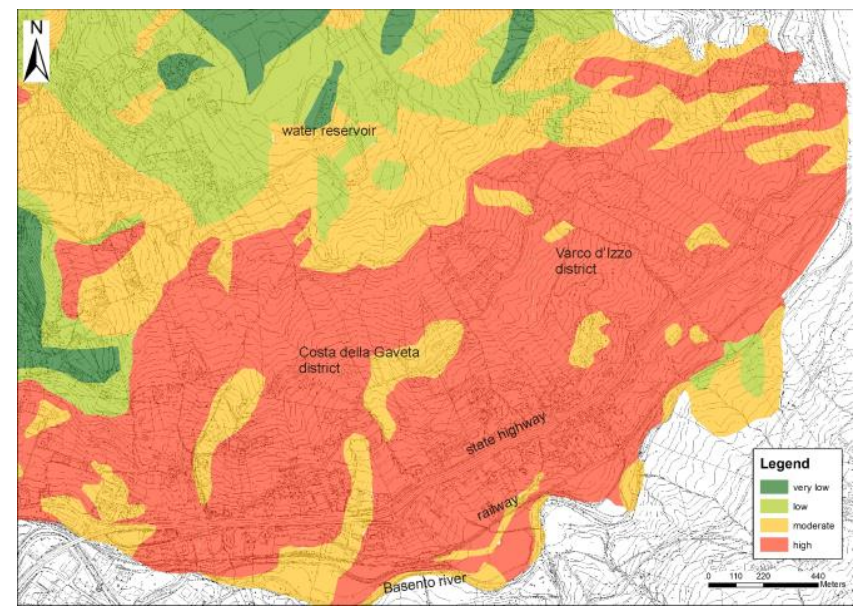

Figure 4 - WoE map for the Costa della Gaveta area.

\section{ACKNOWLEDGMENTS}

TSX data have been provided by the German Aerospace Center through the GEO1589 project (P.I. Davide Notti University of Pavia, Italy).

\section{REFERENCES}

[1] P. A. Rosen, S. Hensley, I. R. Joughin, F. K. Li, S. N. Madsen, E. Rodriguez, and R. M. Goldstein, "Synthetic aperture radar interferometry," Proc. IEEE, vol. 88, no. 3, pp. 333-382, 2000.
[2] M. Scaioni, L. Longoni, V. Melillo and M. Papini, "Remote Sensing for Landslide Investigations: An Overview of Recent Achievements and Perspectives", Remote Sens., vol.6, 2014. doi:10.3390/rs60x000x.

[3] A. Perrone, A. Iannuzzi, V. Lapenna, P. Lorenzo, S. Piscitelli, E. Rizzo and F. Sdao, "High-resolution electrical imaging of the Varco d'Izzo earthflow (southern Italy)", Journal of Applied Geophysics, vol.56, pp. 17-29, 2004.

[4] G. Colangelo, V. Lapenna, A. Perrone, S. Piscitelli and L. Telesca, "2D Self-Potential tomographies for studying groundwater flows in the Varco d'Izzo landslide (Basilicata, southern Italy)" Engineering Geology, vol.88, pp. 274-286, 2006.

[5] S. Calcaterra, C. Cesi, C. Di Maio, P. Gambino, K. Merli, M. Vallario and R. Vassallo, "Surface displacements of two landslides evaluated by GPS and inclinometer systems: a case study in Southern Apennines, Italy", Natural Hazards, vol.61, pp. 257-266, 2012.

[6] A. Sowter, L. Bateson, P. Strange, K. Ambrose, and M. F. Syafiudin, "DInSAR estimation of land motion using intermittent coherence with application to the South Derbyshire and Leicestershire coalfields," Remote Sens. Lett., vol. 4, no. 10, pp. 979-987, 2013.

[7] L. Bateson, F. Cigna, D. Boon, and A. Sowter, "The application of the Intermittent SBAS (ISBAS) InSAR method to the South Wales Coalfield, UK," Int. J. Appl. Earth Obs. Geoinf., vol. 34, pp. 249-257, 2015.

[8] L. Mattioni, P. Shiner, E. Tondi, S. Vitale, G. Cello, "The Argille Varicolori Unit of Lucania (Italy): a record of tectonic offscraping andgravity sliding in the Mesozoic-Tertiary Lagonegro Basin, southern Apennines", Geological Society, London, Special Publications, vol.262, pp. 277-288, 2006.

[9] P. Blanco-Sanchez, J. J. Mallorquí, S. Duque, D. Monells, "The Coherent Pixels Technique (CPT): An advanced DInSAR technique for nonlinear deformation monitoring", Pure and Applied Geophysics, vol. 165, pp. 1167-1194, 2008.

[10] A. Novellino, A. De Agostini, D. Di Martire, M. Ramondini, M. Floris, D. Calcaterra, "Using Data from Multiple SAR Sensors in Landslide Characterization: Case Studies from Different Geomorphological Contexts in Italy" Engineering Geology for Society and Territory, vol.2, pp. 395-398, 2015.

[11] C. Di Maio, R. Vassallo, M. Vallario, "Plastic and viscous shear displacements of a deep and very slow landslide in stiff clay formation”, Engineering Geology, vol.162, pp. 53-66, 2013.

[12] C.J. Van Westen, "Application of Geographic Information Systems to Landslide Hazard Zonation", PhD thesis, Technical University Delft: 245 pp., 1993. 